\title{
STORYTELLING MENGGUNAKAN BONEKA TANGAN OLEH GURU: DAPATKAH MENINGKATKAN KETERAMPILAN REGULASI EMOSI ANAK TK A?
}

\author{
Siti Maulina Nuryani Karnaen dan Lucia R. M. Royanto \\ Fakultas Psikologi, Universitas Indonesia \\ Jalan Lingkar Kampus Raya Mawar 53 8, Pondok Cina, Beji, Jawa Barat 16424 \\ E-mail: siti.maulina.nk@gmail.com
}

Diserahkan 27 Januari 2019; Diterima 12 Juli 2019; Dipublikasikan 01 Agustus 2019

\begin{abstract}
ABSTRAK
Penelitian ini bertujuan untuk melihat efektivitas storytelling menggunakan boneka tangan dalam meningkatkan keterampilan regulasi emosi anak TK A di sekolah. Desain penelitian ini adalah kuasi eksperimental dengan pemberian pelatihan praintervensi kepada guru, intervensi guru kepada anak, serta monitoring. Sampel dalam penelitian ini adalah dua kelompok TK A pada dua sekolah yang berbeda di Tanah Sareal (Bogor) dengan membaginya dalam kelompok kontrol dan kelompok eksperimen ( $\mathrm{n}=20$ ). Pemilihan subjek menggunakan teknik purposive sampling dan teacher nomination, yakni anak TK A yang bersekolah di Tanah Sareal, tidak termasuk anak berkebutuhan khusus (ABK), serta memiliki keterampilan regulasi emosi lebih rendah dibanding teman kelasnya. Data diperoleh melalui total skor dari alat ukur regulasi emosi anak pada pretest, posttest 1 , dan posttest 2, diperkaya dengan wawancara dan rekaman video. Hasil uji Wilcoxon menunjukkan terdapat perbedaan yang signifikan pada kelompok eksperimen sejak posttest 1 dilakukan $(0,005<0,05)$ dibanding kelompok kontrol $(0,546>0,05)$. Perilaku stabil hingga posttest 2 dilakukan pada kelompok eksperimen $(0,000<0,05)$ dan tidak ada perubahan signifikan pada kelompok kontrol $(0,572>0,05)$ diukur menggunakan uji Friedman. Dapat disimpulkan bahwa intervensi yang diberikan efektif untuk meningkatkan keterampilan regulasi emosi anak TK A.
\end{abstract}

Kata kunci: regulasi emosi; anak tk a; guru; storytelling; boneka tangan.

\section{STORYTELLING USING HAND PUPPET BY TEACHER: COULD IT PROMOTE KINDERGARTENER'S EMOTION REGULATION SKILL?}

\begin{abstract}
This study aims to look the effectiveness of storytelling using hand puppets in improving kindergartener's emotion regulation skills. This study used quasi-experimental design, providing pre-intervention training for teacher, teacher-to-child intervention, and monitoring. The population were all kindergarteners in Tanah Sareal (Bogor) by making two school as sample divided into control group and experimental group $(n=20)$. Subjects were selected using purposive sampling technique and teacher nomination, namely kindergartener who attended school in Tanah Sareal area, excluded children with special needs, and had lower emotion regulation skill than their classmates. Data were obtained through total scores from children emotion regulation measurement from pretest, posttest 1 , and posttest 2, enriched with interviews and video recordings. Result from Wilcoxon test showed significant difference performed since posttest 1 in experimental group $(0,005<0,05)$ compared to control group $(0,546>0,05)$. The behaviour was stable until posttest 2 in experimental group $(0,000<0,05)$ and there was no significant changes in control group $(0,572>0,05)$ using Friedman test. Therefore, it could be concluded that the intervention is effective to promote children's emotion regulation's skill.
\end{abstract}

Keywords: emotion regulation; kindergarten; teacher; storytelling; hand puppet 


\section{PENDAHULUAN}

Keterampilan menguasai emosi dasar penting bagi anak usia dini sebelum memasuki emosi sekunder yang lebih kompleks (Plutchik, 1980 dalam Henniger, 2009). Emosi dasar yang dimaksud adalah senang, sedih, takut, dan marah yang dianggap telah terbentuk sejak lahir. Emosi juga dibagi ke dalam dua bentuk, yakni emosi positif seperti antusiasme, senang, dan cinta, sedangkan emosi negatif misalnya cemas, marah, sedih, dan perasaan bersalah (Denham, 2007; Santrock, 2011). Menurut Charlesworth (2017), anak harus memahami bahwa setiap orang pasti memiliki emosi positif dan negatif. Ia berhak merasakan emosinya dan tidak menahan emosi negatif demi kesehatan mentalnya. Meski demikian, tidak berarti bahwa anak dapat mengeluarkan emosi negatif seenaknya. Misalnya ketika mengalami emosi marah, tidak apa-apa bagi anak untuk mengekspresikannya namun tidak dalam bentuk yang berlebihan seperti mengarah pada perilaku tantrum, merusak, dan sebagainya.

Kenyataannya, anak sudah menunjukkan emosi negatif namun cenderung masih secara berlebihan ketika berusia 3-5 tahun, seperti tantrum, berteriak dan berbicara dengan nada tinggi, berperilaku kasar kepada teman ketika ada konflik, cenderung egois dan kurangnya toleransi, serta menunjukkan sikap frustrasi ketika menyelesaikan tugas bantu diri (Djulaekah, 2013; Santry \& Irtanti, 2014; Putri, 2017). Adanya kesenjangan dalam kenyataan yang ada di lapangan dengan kondisi ideal yang diharapkan muncul pada anak prasekolah membuat masalah-masalah perilaku semakin bermunculan.

Hal ini terjadi karena anak memasuki lingkungan baru, antara lain sekolah (Morrison, 2009). Saat itu, anak memiliki urgensi penerimaan pertemanan (peer acceptance). Berbagai masalah perilaku yang telah disebutkan sebelumnya dapat diakibatkan oleh limitasi anak pada usia prasekolah, yakni egosentris. Egosentris adalah keterbatasan anak dalam melihat sesuatu hanya dari sudut pandangnya sendiri (Santrock, 2011). Akibatnya, segala tindakannya akan berpusat pada standar dirinya. Kebutuhan akan pertemanan yang berseberangan dengan limitasi anak tersebut menjadi sebab munculnya konflik seperti perilaku bermasalah pada anak.

Untuk mengatasi konflik yang ditimbulkan, dibutuhkan keterampilan yang baik dalam aspek emosi, yakni regulasi emosi. Regulasi emosi adalah kemampuan untuk mengatur dorongan emosi yang dirasakan agar dapat merespon atau berperilaku secara tepat sesuai situasinya (Denham, 2006; Santrock, 2011). Keterampilan regulasi emosi yang baik artinya mampu mengatur emosi yang dimiliki agar sesuai dengan lingkungan, mengatasi emosi negatif, serta mempertahankan emosi positifnya (Shields \& Cicchetti, 1998; Thompson, 1994 dalam Dereli, 2017).

Idealnya, anak pada usia 4-5 tahun sudah lebih baik dalam memahami emosi dibandingkan usia sebelumnya. Hal ini akan terlihat dari kemampuan mengungkapkan emosi yang lebih baik, diikuti peningkatan keterampilan meregulasi emosi seiring bertambahnya usia memasuki masa prasekolah (Copple \& Bredekamp, 2009; Cole et. al., 2009 dalam Santrock, 2011). Pentingnya keterampilan ini dimiliki anak usia 45 tahun karena adanya masa berpisah dari significant others seperti orangtua atau pengasuh utama, berganti dengan penyesuaian terhadap orang baru seperti guru dan teman sebaya. Masa transisi ini akan berpengaruh terhadap perilaku anak saat belajar di taman kanakkanak, sehingga keterampilan regulasi emosi diperlukan untuk meningkatkan kebahagiaan diri anak (Papalia \& Martorell, 2014), hubungan dengan teman sebaya (Santrock, 2011; Hoffman \& Russ, 2012), dan prediksi kesuksesan di sekolah (Graziano et al., 2007).

Anak pada masa prasekolah mulai mengerti pentingnya penerimaan guru dan berusaha menjadi yang terbaik (Morrison, 2009). Keterampilan regulasi emosi yang rendah cenderung membuat anak menunjukkan perilaku yang kurang baik sehingga mempengaruhi kemampuan adaptasinya di sekolah. Oleh karenanya, perlu adanya stimulasi dari guru untuk membantu meningkatkan keterampilan tersebut. Selain karena lamanya waktu yang dihabiskan di sekolah, dapat membuat anak lebih mudah menginternalisasi informasi ketika diberikan oleh guru dibandingkan oleh orangtua (Shumaker \& Heckel, dalam Rahiem, Abdullah, \& Rahim, 2012). Hal ini disebabkan otoritas guru yang lebih tinggi dan penjabaran konsekuensi yang lebih jelas dalam lingkungan sekolah sehingga anak cenderung melakukan active-learning dibandingkan saat di rumah. Apabila diberikan pengajaran yang fokus kepada anak, kecenderungan peningkatan minat dan motivasi bagi anak untuk belajar dan menginternalisasi apa yang dipelajari akan tinggi (Berns, 2013).

Materi pengajaran yang berfokus kepada anak harus sesuai dengan tahap perkembangannya. Anak TK A atau kisaran usia 4-5 tahun cenderung sudah semakin aktif melakukan eksplorasi dan ekspresi diri dalam berbagai bentuk (Morrison, 2009). Hal ini disebabkan pertumbuhan yang pesat pada fisiknya. Perkembangan fisik tersebut akan mempengaruhi otak sehingga perkembangan kognitif dan bahasanya sudah lebih baik. Peningkatan tersebut memberikan kesempatan bagi anak untuk mengendalikan pikiran dan tindakannya (Vieillevoye \& Nader-Grosbois, 2008). Hal ini berkaitan juga dengan aspek sosioemosional anak yang memasuki tahapan initiative versus guilt sehingga anak ingin melakukan berbagai hal namun juga mulai belajar bahwa dalam setiap perilaku diperlukan penerimaan dari lingkungan (Papalia \& Martorell, 2014).

Sesuai teori Piaget, anak pada usia prasekolah (2-7 tahun) berada pada tahapan praoperasional, sehingga salah satu proses belajar yang dilakukan adalah dengan imitasi atau peniruan. Santrock (2011) menyebutkan bahwa wujud perilaku hasil peniruan yang dilakukan akan dipengaruhi oleh limitasi pada anak, yakni kepercayaan benda mati sebagai sesuatu yang hidup (animisme) dan keterbatasan dalam sudut pandang berpikir yang berpusat pada dirinya 
(egosentrik). Untuk mempermudah dalam mempelajari konsep yang abstrak seperti regulasi emosi, anak perlu diberikan objek yang konkrit dan media yang dekat dengan dirinya.

Pada lokasi penelitian, belum diberikan secara khusus stimulasi yang dapat membantu keterampilan regulasi emosi anak. Hal ini disebabkan karena guru tidak memiliki paduan yang jelas dalam cara melaksanakannya. Oleh karenanya, dilakukan alternatif pembelajaran menggunakan boneka tangan untuk melakukan storytelling. Dasar pemikirannya adalah adanya temuan yang menyebutkan bahwa anak akan cenderung lebih banyak berfokus kepada boneka sehingga membuat pendongeng dapat lebih luwes untuk menceritakan kisahnya. Selain itu anak lebih menikmati jalannya cerita, juga menumbuhkan kedekatan dengan pendongeng dan teman-teman yang mendengarkan cerita (Greene, 1996; Liang et.al., 2017).

Boneka mengilustrasikan perilaku atau konsep yang ingin disampaikan dengan mengungkapkannya secara lisan. Tidak hanya itu, boneka juga mencontohkan perilaku yang dimaksud sebagai upaya memperdalam pemahaman anak. Anak-anak yang menyimak acara Sesame Street akan lebih baik dalam mengatasi konflik, menunjukkan perilaku positif, dan terlibat dalam sedikit stereotip dibandingkan yang tidak menonton. Astell-Burt (dalam Hatamiya, 2011) juga menambahkan, metode boneka tangan cocok untuk menggambarkan kehidupan sehari-hari karena dapat mewakili konsep ide dan emosi dalam bentuk audio dan visual sehingga dapat merangsang imajinasi dan peran aktif anak.

Bentuk nyata secara audio dan visual tersebut menunjang kemampuan regulasi anak. Perkembangan kognitif pada anak usia prasekolah masih berada pada tahap praoperasional sehingga kesulitan untuk memahami sesuatu yang sifatnya abstrak seperti emosi. Hal ini berseberangan dengan pendapat PeñaSarrionandiaetal., Mikolajczak, \& Gross (2015) yang menyebutkan bahwa untuk mengubah emosi yang dimiliki harus melibatkan aspek kognitifnya. Pasupathi, Wainryb, Mansfield, dan Bourne (2016) menyebutkan perubahan kognitif (cognitive change) khususnya dalam penilaian ulang terhadap suatu emosi (reappraisal) akan memberikan perubahan perilaku yang berlangsung lebih lama dibandingkan memberikan distraksi kepada anak. Oleh karena itu, penggunaan media yang konkrit seperti boneka tangan akan cocok untuk pengajaran regulasi emosi yang menyasar kepada kognitif anak.

Proses perubahan kognitif dalam proses pembelajaran melalui media berkaitan dengan metode pembelajaran observasional. Hal ini disebabkan untuk mempelajari sesuatu, anak melibatkan aspek kognitif karena tidak harus melakukan sendiri namun dapat melalui pengamatan terhadap orang lain (Santrock, 2006; King, 2010). Boneka tangan dalam hal ini dianggap sebagai orang lain bagi anak karena keterbatasannya dalam berpikir, yakni animisme. Boneka dianggap sosok yang menarik bagi anak sehingga cocok untuk menjadi model dalam anak melakukan imitasi perilaku. Brouzos, Vassilopoulos, dan Moschou (2016) menyarankan penyampaian konsep dalam bentuk cerita dengan karakter tertentu lebih efektif bagi anak dibandingkan pemberian contoh secara riil.

Berdasarkan pemaparan di atas, penelitian ini bermaksud untuk memberikan stimulasi regulasi emosi kepada anak melalui guru. Guru sebagai sosok berpengaruh terhadap anak akan diberikan pelatihan praintervensi terlebih dahulu untuk diasah pengetahuan tentang tahap perkembangan anak, regulasi emosi serta keterampilan storytelling. Penelitian ini bertujuan melihat efektivitas storytelling melalui boneka tangan terhadap keterampilan regulasi emosi anak TK A.

\section{METODE}

\section{Partisipan}

Pengambilan sampel dalam penelitian ini menggunakan teknik purposive sampling. Hal ini disebabkan tidak semua anak diobservasi secara mendetil. Terdapat karakteristik yang harus dipenuhi oleh anak yang dilibatkan dalam penelitian ini. Pemilihan subjek dilakukan oleh guru kelas dengan cara teacher nomination, yang mana guru melakukan pengurutan terhadap anak-anak berdasarkan subjektivitas sesuai indikator-indikator dari suatu perilaku yang ingin dilihat (Dowdy, Doane, Eklund, \& Dever, 2011). Oleh karena guru yang melakukan intervensi kepada anak, terdapat karakteristik guru yang perlu dipenuhi, yakni: 1) merupakan guru yang mengajar dalam kelas tersebut; dan 2) telah mengikuti rangkaian pelatihan praintervensi yang diberikan oleh peneliti. Karakteristik anak sebagai subjek penelitian adalah: 1) anak TK A yang bersekolah di area Tanah Sareal (kisaran usia 4-5 tahun); 2) tidak termasuk anak berkebutuhan khusus (ABK); dan 3) termasuk dalam anak-anak urutan terbawah yang memiliki keterampilan regulasi emosi rendah dibanding teman kelasnya. Jumlah sampel yang didapat pada kelompok kontrol dan eksperimen masingmasing sebanyak 10 anak $(\mathrm{n}=20)$. Penelitian ini merupakan pretest-posttest nonequivalent control group design tanpa adanya randomisasi dan sedikitnya kontrol sehingga termasuk penelitian kuasi eksperimental (Gravetter \& Forzano, 2012).

\section{Prosedur Penelitian}

Penelitian ini dilaksanakan selama tiga minggu di ruang kelas. Kelompok kontrol tidak mendapatkan perlakuan apapun sehingga hanya diberikan tes sebanyak tiga kali (pretest, posttest 1, dan posttest 2). Untuk kelompok eksperimen, minggu pertama peneliti melakukan pelatihan praintervensi kepada guru. Minggu kedua guru melakukan intervensi storytelling kepada anak. Minggu ketiga adalah monitoring terhadap perubahan perilaku anak serta penguatan jika perilaku yang diharapkan belum muncul. 


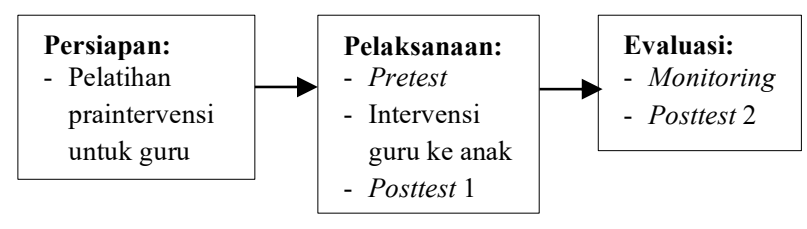

\section{Gambar 1. Tahapan Prosedur Penelitian}

Pelatihan praintervensi kepada guru dilakukan selama tiga hari, berdurasi 1-1,5jam setiap harinya. Secara garis besar setiap harinya terbagi menjadi dua sesi, yakni: 1) pemaparan konsep-konsep serta prosedur; dan 2) pemaparan terkait storytelling dan simulasinya. Guru pun difasilitasi booklet dan boneka tangan sebagai panduan intervensi minggu selanjutnya. Pelaksanaan dilakukan oleh tiga fasilitator. Peneliti memberikan materi tentang tahap perkembangan anak, konsep regulasi emosi, dan prosedur intervensi kepada anak. Storyteller memberikan materi terkait konsep storytelling dan prakteknya. Kofasilitator membantu dalam logistik, dokumentasi, dan tugas teknis lainnya. Penyusunan konten pelatihan praintervensi ini disusun berdasarkan prinsip pembelajaran orang dewasa oleh Knowles, Holton III, dan Swanson (2015).

\section{Tabel 1. Rincian Pelaksanaan Pelatihan Praintervensi untuk Guru}

\begin{tabular}{|c|c|c|c|}
\hline Hari & Pelaksana & Metode & Kegiatan \\
\hline \multirow[t]{3}{*}{1} & Peneliti & $\begin{array}{l}\text { Ceramah, } \\
\text { diskusi }\end{array}$ & $\begin{array}{lr}\text { Penjelasan } & \text { tahap } \\
\text { perkembangan } & \text { anak }\end{array}$ \\
\hline & & & $\begin{array}{l}\text { khususnya pada TK A } \\
\text { serta konsep regulasi. }\end{array}$ \\
\hline & Storyteller & $\begin{array}{l}\text { Ceramah, } \\
\text { diskusi }\end{array}$ & $\begin{array}{l}\text { Penjelasan umum } \\
\text { tentang storytelling. }\end{array}$ \\
\hline \multirow[t]{2}{*}{2} & Peneliti & $\begin{array}{l}\text { Ceramah, } \\
\text { diskusi }\end{array}$ & $\begin{array}{l}\text { Pengulangan materi hari } \\
\text { sebelumnya, penjabaran } \\
\text { prosedur intervensi } \\
\text { kepada anak. }\end{array}$ \\
\hline & Storyteller & $\begin{array}{l}\text { Ceramah, } \\
\text { diskusi, } \\
\text { simulasi }\end{array}$ & $\begin{array}{l}\text { Pemeragaan storytelling } \\
\text { serta pelatihan gerak } \\
\text { tangan dengan boneka } \\
\text { tangan }\end{array}$ \\
\hline \multirow[t]{2}{*}{3} & Peneliti & $\begin{array}{l}\text { Ceramah, } \\
\text { diskusi }\end{array}$ & $\begin{array}{l}\text { Pengulangan materi hari } \\
\text { pertama dan kedua } \\
\text { secara singkat. }\end{array}$ \\
\hline & Storyteller & Simulasi & $\begin{array}{l}\text { Pendampingan terhadap } \\
\text { guru dalam melakukan } \\
\text { storytelling. }\end{array}$ \\
\hline
\end{tabular}

Setelah pelatihan praintervensi untuk guru selesai dilaksanakan, guru mengaplikasikan apa yang telah didapat kepada anak. Intervensi guru kepada anak berlangsung selama tiga hari dengan durasi kurang lebih 30 menit setiap harinya. Guru membagi penjabaran emosi ke dalam dua sesi, yakni pada hari pertama berfokus kepada emosi sedih dan marah, sedangkan hari kedua berfokus kepada emosi takut dan senang. Hari terakhir guru mempersilahkan anak-anak untuk mencoba mempraktekkan storytelling di depan temantemannya.

Konten intervensi guru kepada anak disusun berdasarkan proses pembelajaran observasional, yakni: attention, representation, behavior production, dan motivation (Santrock, 2006; King, 2010; Feist \& Feist, 2012). Ciri pembelajaran ini adalah anak tidak perlu melakukan apapun untuk mempelajari sesuatu (Feist \& Feist, 2012). Ia akan melakukan peniruan terhadap model yang diamati untuk kemudian diproses secara kognitif yang menghasilkan perilaku serupa. Oleh karenanya model yang diamati anak haruslah menarik, sehingga peneliti memilih menggunakan boneka tangan berbentuk monyet bernama Momo dan bebek bernama Bebe.

Tabel 2. Rincian Prosedur Intervensi Guru kepada Anak

\begin{tabular}{|c|c|c|}
\hline Sesi & Metode & Kegiatan \\
\hline Halo-loha & Diskusi & $\begin{array}{l}\text { Mempersiapkan anak untuk } \\
\text { memasuki proses kegiatan } \\
\text { belajar-mengajar (KBM). }\end{array}$ \\
\hline Perasaanku & Diskusi & $\begin{array}{lr}\text { Memberikan } & \text { pemahaman } \\
\text { tentang emosi } & \text { diri dan } \\
\text { memperkenalkan } & \text { boneka } \\
\text { tangan. } & \\
\end{array}$ \\
\hline Ceritaku & $\begin{array}{l}\text { Story- } \\
\text { telling }\end{array}$ & Mengajarkan regulasi emosi. \\
\hline $\begin{array}{l}\text { Tawa } \\
\text { (Tanya- } \\
\text { Jawab) }\end{array}$ & Diskusi & $\begin{array}{l}\text { Mengulang materi regulasi } \\
\text { emosi untuk mengukur } \\
\text { pemahaman anak. }\end{array}$ \\
\hline $\begin{array}{l}\text { Salju } \\
\text { (Sampai } \\
\text { Jumpa) }\end{array}$ & Diskusi & $\begin{array}{l}\text { Mengumumkan akan adanya } \\
\text { pemberian poin reward bagi } \\
\text { yang mampu melakukan } \\
\text { regulasi emosi dalam } \\
\text { kesehariannya. }\end{array}$ \\
\hline
\end{tabular}

Sesi "Halo-loha" dan "Perasaanku" merupakan penguatan proses attention atau atensi pada anak. "Halo-loha" merupakan ice-breaking yang berupaya untuk mendapatkan atensi dan mempersiapkan anak sebelu memasuki proses pengajaran. Sesi "Perasaanku" merupakan sesi transisi yang mana bertujuan untuk menguatkan proses attention dan representation. Setelah perhatian anak terpusat, guru dapat menstimulasi untuk membantu proses penyimpanan informasi (representation). Sesi ini anak akan diajak bernyanyi lagu "Kalau Kau Senang Hati" agar dapat mengekspresikan emosinya melalui kata, mimik muka dan gerak tubuh. Selanjutnya anak dapat diberikan pertanyaan terkait pemahaman emosinya, seperti "Kalau kamu mendapat permen, bagaimana perasaanmu? Mengapa kamu merasa demikian? Seperti apa mukamu saat senang?", dan berlaku juga untuk emosi dasar lainnya (sedih, takut, marah).

Sesi "Ceritaku" juga merupakan perwujudan dari proses representation. Pada sesi ini boneka tangan akan hadir dan menceritakan kisah perjalanan mereka menghadapi dan mengatasi emosi sedih, marah, takut, dan senang. Mengatasi emosi tersebut didasari oleh strategi regulasi emosi, yakni distraction, reappraisal, soothing, serta response modulation (Gross \& Thompson, 2007; Silkenbeumer, Schiller, Holodynski, \& Kärtner, 2016). Untuk membantu anak dalam menampilkan perilaku yang diharapkan atau behavior 
production, dilakukan sesi "Tawa (Tanya-Jawab)". Kegiatan yang dilakukan berupa diskusi dengan anak terkait cerita yang telah disampaikan khususnya pemahaman emosi dan cara menghadapinya serta melakukan restorytelling (penceritaan kembali). Sesi penutup "Salju (Sampai Jumpa) merupakan stimulasi untuk memunculkan motivasi. Dalam hal ini boneka tangan akan mengumumkan pengumpulan poin kepada anak-anak yang dapat mempraktekkan sesuai apa yang dicontohkan oleh Momo dan Bebe.

\section{Alat Ukur}

Alat ukur regulasi emosi anak mengadaptasi alat ukur ERC (Emotion Regulation Checklist) oleh Shields dan Cicchetti (1997) yang sudah dikembangkan oleh Molina et al. (2014), untuk disesuaikan dengan kondisi lapangan. Alat ukur memiliki koefisien Cronbach's Alpha sebesar 0,82 sehingga termasuk alat ukur yang reliabel (Aiken \& Groth-Marnat, 2006). Pernyataan terdiri dari 12 item dengan 4 pilihan jawaban (hampir selalu, sering, kadang-kadang, tidak pernah) dengan rincian dimensi emotion regulation sebanyak 5 item dan dimensi lability/negativity sebanyak 7 item. Dimensi emotion regulation dijelaskan sebagai kapasitas untuk mengelola dan memodulasi emosi sehingga dapat bereaksi secara optimal sesuai lingkungan. Dimensi lability/negativity adalah reaksi emosional yang berlebihan dan perubahan suasana hati yang sering dalam emosinya yang kurang sesuai dengan lingkungan atau stimulus (Shields \& Cicchetti, 1997; Molina et al., 2014). Pengisian alat ukur dilakukan oleh guru. Analisis data menggunakan uji statistik non parametrik Mann Whitney-U, Wilcoxon, dan Friedman dengan membandingkan gain score. Terdapat data pendukung dalam penelitian ini berupa hasil wawancara pendek kepada guru dan orangtua serta rekaman video selama rangkaian intervensi berlangsung.

\section{HASIL DAN PEMBAHASAN}

\section{Data Kuantitatif}

Uji kemampuan awal dilakukan untuk mengetahui ada tidaknya perbedaan yang signifikan antara kelompok kontrol dan eksperimen. Apabila hasil yang didapat tidak berbeda secara signifikan, kedua kelompok tersebut dinyatakan setara. Pengujian dilakukan menggunakan uji statistik Mann Whitney- $U$ dengan membandingkan skor pretest kedua kelompok.

Tabel 3. Hasil Uji Perbedaan Kemampuan Awal Kelompok Kontrol dan Eksperimen

\begin{tabular}{lcccc}
\hline Kelompok & $\boldsymbol{N}$ & Mean Rank & $\boldsymbol{U}$ & Sig \\
\cline { 1 - 2 } Kontrol & 10 & 10,35 & \multirow{2}{*}{48,500} & \multirow{2}{*}{0,912} \\
\hline Eksperimen & 10 & 10,65 & & \\
\hline
\end{tabular}

Berdasarkan tabel di atas, nilai $U$ adalah 48,5 yang mana lebih besar dari $U$ tabel sebesar 23. Demikian halnya dengan nilai $\mathrm{p}$ (Sig) sebesar 0,912 yang lebih besar dari probabilitas 0,05 . Oleh karena nilai U hitung $>\mathrm{U}$ tabel dan $\mathrm{p}$ hitung $>$ probabilitas maka tidak ada perbedaan kemampuan awal yang signifikan antara kelompok kontrol dan kelompok eksperimen. Berbedaan mean rank yang kecil senilai 0,3 menunjukkan bahwa kedua kelompok setara.

Tabel 4. Data Deskriptif Skor Regulasi Emosi Kelompok Kontrol

\begin{tabular}{cccc}
\hline Responden & Pretest & Posttest 1 & Posttest 2 \\
\hline 1 & 35 & 36 & 37 \\
2 & 29 & 32 & 31 \\
3 & 34 & 36 & 36 \\
4 & 35 & 35 & 34 \\
5 & 33 & 32 & 32 \\
6 & 30 & 30 & 28 \\
7 & 34 & 32 & 33 \\
8 & 38 & 39 & 36 \\
9 & 37 & 36 & 37 \\
10 & 38 & 38 & 37 \\
\hline
\end{tabular}

Berdasarkan tabel di atas, perubahan skor yang terjadi pada kelompok kontrol tergolong stabil. Kisaran perubahan berada pada nilai -2 sampai 3. Semua anak tergolong dalam kategori regulasi sedang sejak pretest hingga posttest 2 dilaksanakan.

Tabel 5. Data Deskriptif Skor Regulasi Emosi Kelompok Eksperimen

\begin{tabular}{cccc}
\hline Responden & Pretest & Posttest 1 & Posttest 2 \\
\hline A & 27 & 31 & 32 \\
B & 36 & 38 & 43 \\
C & 37 & 38 & 41 \\
D & 35 & 37 & 40 \\
E & 34 & 37 & 39 \\
F & 30 & 31 & 34 \\
G & 38 & 42 & 41 \\
H & 36 & 40 & 42 \\
I & 36 & 38 & 39 \\
J & 33 & 35 & 37 \\
\hline
\end{tabular}

Kelompok eksperimen terjadi peningkatan secara bertahap dari pretest sampai dengan posttest 2 . Terdapat lima anak dalam kelompok eksperimen mengalami perpindahan kategori yang awalnya tergolong regulasi emosi sedang menjadi regulasi emosi tinggi, yakni Responden B, C, D, G, dan H. Dalam penelitian ini penggolongan dibagi menjadi tiga kategori, yakni rendah $(X \leq 21)$, sedang $(21<X \leq 39)$, dan tinggi $(X>$ 39).

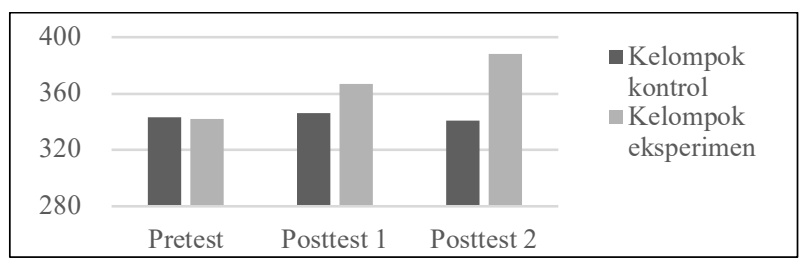

Gambar 1. Grafik Perubahan Total Skor Regulasi Emosi Kelompok Kontrol dan Eksperimen

Berdasarkan gambar di atas, dapat dibandingkan bawah pada kelompok kontrol tidak terjadi perubahan yang banyak dan cukup stabil pada kisaran nilai 340. Lain halnya dengan kelompok eksperimen yang memiliki kemampuan hampir sama 
dengan kelompok kontrol lalu mengalami peningkatan sebanyak dua kali lipat pada saat posttest 2 .

Tabel 6. Hasil Uji Perubahan Masing-masing Kelompok Kontrol dan Eksperimen

\begin{tabular}{lcccc}
\hline \multirow{2}{*}{ Kelompok } & \multicolumn{2}{c}{ Pretest-Posttest 1 } & \multicolumn{2}{c}{ Pretest-Posttest 2 } \\
\cline { 2 - 5 } & $\boldsymbol{Z}$ & Sig & $\begin{array}{c}\text { Chi- } \\
\text { Square }\end{array}$ & Sig \\
\hline Kontrol & $-0,604^{\mathrm{b}}$ & 0,546 & 1,118 & 0,572 \\
Eksperimen & $-2,831^{\mathrm{b}}$ & 0,005 & 18,200 & 0,000 \\
\hline
\end{tabular}

Pengujian dilakukan menggunakan uji Wilcoxon untuk melihat perubahan yang terjadi antara pretest dan posttest 1 serta uji Friedman untuk pretest sampai dengan posttest 2. Berdasarkan tabel di atas, kelompok kontrol memiliki nilai $\mathrm{p}$-value $=0,546$ dan $\mathrm{p}$ value $=0,572$. Kedua nilai tersebut lebih dari probabilitas 0,05 sehingga tidak ada perbedaan yang signifikan selama proses intervensi berlangsung. Sebaliknya, kelompok eksperimen memiliki nilai $\mathrm{p}$-value $=0,005$ dan $\mathrm{p}$-value $<0,000$ sehingga bernilai kurang dari 0,05. Dapat disimpulkan bahwa kelompok eksperimen telah mengalami peningkatan perubahan perilaku sejak diberikan treatment hingga masa intervensi berakhir.

Tabel 7. Hasil Uji Pengaruh Intervensi antara Kelompok Kontrol dan Eksperimen

\begin{tabular}{|c|c|c|c|c|c|}
\hline Uji & Kelompok & $N$ & $\begin{array}{l}\text { Mean } \\
\text { Rank }\end{array}$ & $\boldsymbol{U}$ & Sig \\
\hline \multirow{2}{*}{$\begin{array}{l}\text { Pretest- } \\
\text { Posttest } 1\end{array}$} & Kontrol & 10 & 6,75 & \multirow{2}{*}{12,50} & \multirow{2}{*}{0,003} \\
\hline & Eksperimen & 10 & 14,25 & & \\
\hline \multirow{2}{*}{$\begin{array}{l}\text { Pretest- } \\
\text { Posttest } 2\end{array}$} & Kontrol & 10 & 5,50 & \multirow{2}{*}{0,00} & \multirow{2}{*}{0,000} \\
\hline & Eksperimen & 10 & 15,50 & & \\
\hline
\end{tabular}

Tabel di atas merupakan hasil uji Man Whitney- $U$ yang dilakukan untuk melihat efektivitas intervensi yang diberikan dengan membandingkan gain score-nya. Merujuk pada hasil pretest-posttest 1 , nilai U hitung $<\mathrm{U}$ tabel $(12,50<23)$ serta nilai $\mathrm{p}(\mathrm{Sig})<0,05$ yang artinya terdapat perbedaan signifikan antara gain score pretest-posttest 1 pada kedua kelompok. Selanjutnya apabila dibandingkan antara skor pretestposttest 2 , terlihat bahwa nilai $\mathrm{U}$ hitung $<\mathrm{U}$ tabel $(0,00$ $<23$ ) dan nilai $\mathrm{p}<0,05$ sehingga dapat dipastikan bahwa terdapat perbedaan yang signifikan antara gain score kedua kelompok. Berdasarkan hasil perhitungan di atas, disimpulkan bahwa pemberian intervensi storytelling menggunakan boneka tangan dapat meningkatkan perilaku yang diharapkan muncul, yakni keterampilan regulasi emosi pada anak.

\section{Data Kualitatif}

Saat pelaksanaan intervensi kepada anak, guruguru berpendapat bahwa boneka tangan Monyet dan Bebek sangat menarik minat anak. Hal ini sesuai dengan analisis kebutuhan yang telah dilakukan pada awal penelitian karena di sekolah tersebut tidak pernah bercerita menggunakan media selain buku. Guru mengungkapkan bahwa anak-anak terlihat lebih antusias dari biasanya, terkadang terlalu mendekat ke arah guru. Guru sempat kewalahan karena anak terlihat ingin diikutsertakan dalam proses storytelling. Keadaan tersebut dimanfaatkan oleh guru dengan melibatkan anak dalam bercerita ataupun berhenti sebentar dan memeluk anak yang ingin merebut boneka tangannya.

Guru-guru menyebutkan bahwa sesi "Perasaanku" dan sesi "Tawa" memberikan dampak yang efektif kepada anak. Guru tidak perlu lagi banyak bertanya karena anak lebih aktif untuk mengemukakan pendapat dan beberapa bahkan mempraktekkan ekspresi emosi yang telah ditampilkan dalam cerita dengan cara saling berhadapan dengan temannya. Penguatan perilaku pun dilakukan minggu monitoring berupa pengingatan materi serta pemberian reward berupa pujian dan akses untuk melakukan storytelling dengan boneka tangan.

Saat jam istirahat atau jam bebas, ditemukan juga beberapa kejadian yang dilihat langsung dan terekam dalam video yang menguatkan dampak baik dari storytelling yang telah diberikan, di antaranya:

1. Anak-anak mengajak temannya yang hampir menangis untuk melakukan gerakan deep-breath taking seperti dalam cerita;

2. Terdapat pengulangan kalimat seperti, "Iya kan kaya yang di cerita Momo ya dianya baik ga marah-marah, terus jalan-jalan lagi";

3. Bermain peran menirukan kegiatan storytelling;

4. Anak yang suka memukul mendapat teguran dari temannya sendiri; dan

5. Anak yang mudah takut dengan orang baru mulai mau untuk bersalaman dan menyapa orang baru, salah satunya kepada peneliti.

Informasi tentang perilaku anak diperkaya juga melalui pemberian pertanyaan terbuka dalam bentuk kertas kepada orangtua. Lembar pertanyaan tersebut diberikan sebelum rangkaian intervensi dilakukan untuk untuk melihat gambaran perilaku anak di rumah. Berdasarkan jawaban para orangtua, perilaku yang umumnya masih muncul pada anak adalah menangis jika ditinggal orangtua, anak masih terlihat mudah marah karena frustrasi saat tidak berhasil mengerjakan sesuatu, serta takut bertemu orang atau suasana baru. Selanjutnya dilakukan wawancara setelah rangkaian intervensi selesai yang bertujuan untuk melihat perilaku anak di rumah serta perubahan perilakunya sebelum dan setelah diberikannya intervensi. Orangtua mengatakan bahwa tidak banyak perubahan yang terjadi, tetapi terdapat beberapa temuan perilaku yang cukup terlihat, misalnya anak terlihat antusias saat bercerita tentang kegiatan storytelling di sekolah, mau berdiskusi dengan orangtua ketika merasakan emosi sedih atau marah meskipun berdebat terlebih dahulu, serta muncul rasa empati yang ditunjukkan dengan memeluk saat melihat ibu sedih.

Penelitian ini menggunakan metode storytelling dengan boneka tangan untuk meningkatkan regulasi emosi anak. Berdasarkan skor kelompok kontrol dan kelompok eksperimen, terlihat adanya perbedaan hasil yang membuktikan efektivitas metode yang digunakan. Kelompok kontrol tidak mengalami perbedaan yang sgnifikan selama rangkaian penelitian 
dilakukan, sedangkan kelompok eksperimen sebaliknya. Selanjutnya ketika dibandingkan gain score antara keduanya, terdapat perbedaan yang signifikan. Hal ini menunjukkan bahwa perbedaan yang signifikan dalam kelompok eksperimen tersebut merupakan bukti bahwa metode yang digunakan dapat meningkatkan regulasi emosi anak TK A.

Pelatihan praintervensi untuk guru tersebut sudah cukup sesuai dengan teori prinsip pembelajaran orang dewasa. Meski demikian, guru terlihat kurang berkomitmen dalam melakukan intervensi kepada anak sesuai prosedur yang dilatihkan. Pelaksanaan pelatihan yang dilaksanakan setelah jam KBM serta berlangsung cukup lama membuat guru terlihat kurang fokus dalam menjalaninya (Knowles, Holton III, dan Swanson, 2015).

Selanjutnya, reaksi positif yang ditampilkan oleh anak selama proses intervensi berlangsung membuktikan bahwa untuk meningkatkan fokus dan minat anak, diperlukan media yang dekat dengan dirinya. Pemilihan jenis cerita fabel yang menjadikan binatang sebagai tokoh (Huff, 1998) cukup sesuai karena binatang Monyet dan Bebek yang ditampilkan dalam cerita merupakan binatang yang dikenal oleh anak. Pemanfaatan media boneka tangan Monyet dan Bebek juga sejalan dengan limitasi perkembangan kognitif anak yang menganggap benda mati sebagai sesuatu yang hidup atau animism (Santrock, 2011).

Temuan respon guru sesuai strategi regulasi emosi terhadap perilaku anak contohnya dari pemberian pelukan serta melibatkan anak dalam proses cerita. Gross dan Thompson (2007) menyebutkan dua dari empat strategi regulasi emosi adalah soothing (pemberian rasa nyaman) dan reappraisal (penilaian kembali untuk menimbulkan respon baru). Pemberian pelukan saat anak terlihat kesal dan ingin merebut boneka tangan merupakan contoh soothing. Pelibatan anak dalam proses cerita merupakan realisasi dari reappraisal.

Kedekatan yang ditimbulkan antara guru dan anak berdasarkan data kualitatif merupakan salah satu keunggulan dari storytelling menggunakan boneka tangan. Hal ini disebabkan guru tidak perlu terpaku dengan buku atau tulisan sehingga dapat melakukan improvisasi dan anak menikmati jalannya cerita bersama teman-temannya (Liang et al., 2017). Meski demikian, guru terlihat kurang maksimal dalam memberikan stimulasi regulasi emosi kepada anak. Guru lebih banyak berfokus kepada isi cerita tanpa mencoba untuk melakukan scaffolding dalam menggali pengetahuan dan respon anak selama bercerita.

Keunggulan dalam penggunaan metode ini juga terlihat pada setiap sesinya. Hal ini tentunya karena setiap sesi menggunakan dasar teori proses pembelajaran observasional yang dikemukakan oleh Bandura, yakni attention, representation, behavior production, dan motivation (Santrock, 2006; Feist \& Feist, 2012). Kemampuan anak dalam menceritakan kembali dan saling memeragakan ekspresi emosi kepada temannya merupakan bagian dari representation atau penyimpanan informasi. Dalam hal ini terjadi rehearsal atau pengulangan dalam bentuk verbal dan non verbal sehingga mengalami retention atau tersimpan dalam ingatan (Santrock, 2006; King, 2010; Feist \& Feist, 2012). Contoh lainnya adalah pemberian reward kepada anak. Terlihat dari perbandingan skor posttest 1 dan posttest 2 pada kelompok eksperimen yang mengalami peningkatan. Hal ini membuktikan bahwa adanya motivasi eksternal dapat membantu dalam proses behavior production.

Temuan hasil pengamatan dan video yang telah dipaparkan sebelumnya menggambarkan anak saling mengingatkan dan mengulang isi cerita bahkan saat kegiatan bebas berlangsung di sekolah. Hal ini membuktikan bahwa kehadiran teman juga dapat meningkatkan regulasi emosi yang disebabkan oleh adanya penerimaan teman (peer acceptance). Ketika anak tidak dapat meregulasi emosi negatifnya, anak akan dijauhi oleh teman-temannya (Santrock, 2011) sehingga adanya saling mengingatkan antar teman untuk mencapai kebutuhan anak akan penerimaan teman tersebut. Hal ini juga menguatkan salah satu faktor eksternal dalam memengaruhi regulasi emosi anak, yakni environment atau lingkungan (Gross \& Thompson, 2007). Dapat disimpulkan bahwa melibatkan teman-teman di kelas yang tidak termasuk fokus penelitian dalam proses intervensi dapat membantu dalam peningkatan regulasi emosi anak.

Berdasarkan hasil wawancara dengan orangtua, dapat dikatakan bahwa perubahan perilaku yang diharapkan tidak terlalu muncul di rumah. Perubahan skor pada anak yang tidak terlalu banyak meningkat dapat menjadi bukti secara statistik. Orangtua di rumah sebagai mikrosistem terdekat anak (Berns, 2013) perlu diberikan penguatan yang serupa seperti di sekolah. Apabila bentuk pengasuhan orangtua kepada anak tidak dikontrol, peningkatan perilaku yang telah ditunjukkan di sekolah berpotensi tidak muncul di rumah. Hal ini karena pola pengasuhan orangtua menjadi salah satu faktor eksternal bagi anak dalam meregulasi emosinya (Gross \& Thompson, 2007). Hal ini dibuktikan dari hasil penelitian Umami (2015) yang menyebutkan bahwa anak dengan regulasi emosi yang tinggi disebabkan oleh gaya pengasuhan orangtua.

\section{SIMPULAN}

Penelitian ini menunjukkan bahwa pemberian storytelling menggunakan boneka tangan kepada anak dapat meningkatkan keterampilan regulasi emosinya. Kekuatan penelitian terletak pada materi pelatihan guru berbasis prinsip pembelajaran orang dewasa, materi intervensi kepada anak yang mengacu proses pembelajaran observasional, serta adanya rehearsal antara guru dengan anak dan antar anak. Bagi penelitian selanjutnya, disarankan untuk memperbanyak frekuensi pertemuan pelatihan praintervensi kepada guru namun mengurangi durasi dalam setiap pertemuannya. Hal ini bertujuan untuk menjaga motivasi guru dalam 
melakukan intervensi kepada anak. Pelatihan yang diberikan juga perlu terintegrasi di rumah untuk orangtua anak sehingga keterampilan regulasi emosi anak yang telah meningkat lebih menetap. Diperlukan kontrol yang lebih ketat terhadap komitmen guru dalam pelaksanaan intervensi, konten yang lebih memengaruhi motivasi internal guru, serta faktor lingkungan rumah anak. Randomisasi juga perlu diusahakan agar hasil lebih menggambarkan populasi yang diteliti.

\section{DAFTAR PUSTAKA}

Aiken, L. R., \& Groth-Marnat, G. (2006). Psychological testing and assesment (12 ${ }^{\text {th }}$ ed.). Boston: Pearson Education Group, Inc.

Berns, R. M. (2013). Child, family, school, community: Socialization and support $\left(9^{\text {th }}\right.$ ed.). United States of America: Cengage Learning, Inc.

Brouzos, A., Vassilopoulos, S. P., \& Moschou, K. (2016). Utilizing storytelling to promote emotional wellbeing of children with a distinct physical appearance: The case of children who wear eyeglasses. The European Journal of Counselling Psychology: 4(1), 62-76.

Charlesworth, R. (2017). Understanding child development $\left(10^{\text {th }}\right.$ ed.). USA: Cengage Learning.

Denham, S. A. (2006). The emotional basis of learning and development in early childhood education. In B. Spodek \& O. N. Saracho (Eds.), Handbook of research on the education of young children (pp. 85-103). Mahwah, NJ: Lawrence Erlbaum Associates.

Denham, S. A. (2007). Dealing with feelings: How children negotiate the worlds of emotions and social relationships. Cognitie, Creier, Comportament/Cognition, Brain, Behavior, 11(1), $1-48$.

Dereli, E. (2017). Prediction of emotional understanding and emotion regulation skills of 4-5 age group children with teacher-child relations. European Journal of Education Studies, 3(5), 59-78.

Djulaekah, E. (2013). Meningkatkan kemampuan emosional melalui permainan ular naga anak kelompok b di tk hidayatus shibyan. Jurnal PAUD Teratai, 2(2).

Dowdy, E., Doane, K., Eklund, K., \& Dever, B. V. (2011). A comparison of teacher nomination and screening to identify behavioral and emotional risk within a sample of underrepresented students. Journal of Emotional and Behavioral Disorders, 21(2), 127137.

Feist, J \& Feist, G. (2012). Theories of personality ( $8^{\text {th }}$ ed.). New York: McGraw-Hill Higher Education.

Gravetter, F. J. \& Forzano, L. B. (2012). Research methods for the behavioral sciences ( $4^{\text {th }}$ ed.). USA: Wadsworth, Cengage Learning.

Graziano, P. A., Reavis, R. D., Keane, S. P., \& Calkins, S. D. (2007). The role of emotion regulation and children's early academic success. J Sch Psychol, 45(1), 3-19.

Greene, E. Storytelling: Art and technique ( $3^{\text {rd }}$ ed.). USA: Greenwood Publishing Group.
Gross, J. J., \& Thompson, R. A. (2007). Emotion regulation conceptual foundations. In J. J. Gross (Ed.), Handbook of emotion regulation (pp. 3-24). New York: Guilford Press.

Hoffman, J. \& Russ, S. (2012). Pretend play, creativity, and emotion regulation in children. Psychology of Aesthetics, Creativity, and the Arts, 6(2), 175-184.

King, L. (2010). The science of psychology: An appreciative view ( $2^{\text {nd }}$ ed.). New York: McGrawHill Professional.

Knowles, M. S., Holton III, E. F., \& Swanson, R. A. (2015). The adult learner: The definitive classic in adult education and human resource development ( $8^{\text {th }} \quad$ ed.). $\quad$ Retrieved from https://books.google.co.id/books?id=1We2BQAAQ BAJ\&printsec $=$ frontcover\&source $=\mathrm{gbs} \_$ge_summar $\mathrm{y} \_\mathrm{r} \& \mathrm{cad}=0 \# \mathrm{v}=$ onepage $\& \mathrm{q} \& \mathrm{f}=$ false

Kumar, R. (2005). Research methodology: A-step-by-step guide for beginner $\left(2^{\text {nd }}\right.$ ed.). London: Sage Publications.

Liang, H., Chang, J., Kazmi, I. K., Zhang, J. J., \& Jiao, P. (2017). Hand gesture-based interactive puppetry system to assist storytelling for children. Vis Comput, 33(4), 517-531.

Molina, P., Sala, M. N., Zappulla, C., Bonfigliuoli, C., Cavioni, V., Zanetti, M. A., Baiocco, R., Laghi, F., Pallini, S., Stasio, S. D., Raccanello, D., \& Cicchetti, D. (2014). The emotion regulation checklist - italian translation: Validation of parent and teacher. European Journal of Developmental Psychology, 11(5), 624-634.

Morrison, G. S. (2009). Early childhood education today $\left(11^{\text {th }}\right.$ ed.). New Jersey: Pearson Education, Inc.

Papalia, D. E. \& Martorell, G. (2014). Experience human development (13 ${ }^{\text {th }}$ ed.). New York: McGraw-Hill International Edition.

Pasupathi, M., Wainryb, C., Mansfield, C. D., \& Bourne, S. (2016). The feeling of the story: Narrating to regulate anger and sadness. Cognition and Emotion, $1-18$.

Peña-Sarrionandiaetal, A., Mikolajczak, M., \& Gross, J. J. (2015). Integrating emotion regulation and emotional intelligence traditions: A meta-analysis. Frontier in Psychology, 6, 1-27.

Putri, C. I. H. (2017). Pelatihan regulasi emosi anak usia prasekolah (3-4 tahun). Jurnal Pendidikan Anak, 6(2), 190-202.

Rahiem, M. D. H., Abdullah, N. S. M., \& Rahim, H. (2012). School culture and the moral development of children. ProQuest, 56(23), 114-118.

Santrock, J. W. (2006). Educational psychology ( $3^{\text {rd }}$ ed.). Boston: McGraw-Hill.

Santrock, J. W. (2011). Child development $\left(13^{\text {th }}\right.$ ed.). New York: McGraw-Hills Humanities.

Santy, W. H. \& Irtanti, T. A. (2014). Pola asuh orang tua mempengaruhi temper tantrum pada anak usia 2-4 tahun di paud darun najah desa gading, jatirejo, mojokerto. Jurnal Ilmiah Kesehatan, 7(12), 73-81.

Shields, A. \& Cicchetti, D. (1997). Emotion regulation among school-age children: The development and validation of a new criterion q-sort scale. Developmental Psychology, 33(6), 906-916. 
Jurnal Psikologi Sains dan Profesi (Journal Psychology of Science and Profession)

Vol. 3, No. 2, Agustus 2019: 75-82

Shields, A. \& Cicchetti, D. (1998). Reactive aggression among maltreated children: the contributions of attention and emotion dysregulation. Journal of Clinical Child Psychology, 27(4), 381-394.

Silkenbeumer, J., Schiller, E., Holodynski, M., \& Kärtner, J. (2016). The role of co-regulation for the development of socialemotional competence in early childhood. Journal of Self-Regulation and Regulation, 2(2016), 17-32.

Vieillevoye, S. \& Nader-Grosbois, N. (2008). Selfregulation during pretend play in children with intellectual disability and in normally developing children. Research in Developmental Disabilities, 29(2008), 256-272. 